\title{
Liberalismo / Conservadorismo Sexual: Proposta de uma Medida Multi-Fatorial
}

\section{Sexual Liberalism / Conservatism: Proposal of a Multi-Factorial Measurement}

\author{
Valeschka M. Guerra \& Valdiney V. Gouveia* \\ Universidade Federal da Paraíba, João Pessoa, Brasil
}

\begin{abstract}
Resumo
Este estudo objetiva apresentar uma medida multi-fatorial de liberalismo / conservadorismo sexual. Partiu-se do Questionário de Atitudes Sexuais, sendo acrescentados novos itens. Para tanto, foram realizados dois estudos. No primeiro, os participantes responderam o Questionário de Atitudes Sexuais, dividido em duas sub-escalas (Self e Other), e questões demográficas. Os resultados das análises fatoriais exploratórias evidenciaram um fator geral de liberalismo / conservadorismo sexual. No segundo estudo os participantes responderam o Questionário de Liberalismo / Conservadorismo Sexual (QLCS), a Escala de Conservadorismo Moral, a Escala de Tradicionalismo Moral e questões demográficas. Mediante uma análise fatorial confirmatória, comprovou-se a estrutura multi-fatorial do QLCS, que revelou índices aceitáveis de bondade de ajuste. Os Alfas de Cronbach encontrados para os fatores de segunda ordem foram 0,88 (Self) e 0,90 (Other). Todos os fatores do liberalismo se correlacionaram entre si e com as escalas de conservadorismo e tradicionalismo moral, comprovando a validade convergente do instrumento psicométrico, que se mostrou adequado para utilização no contexto brasileiro.
\end{abstract}

Palavras-chave: Liberalismo sexual; conservadorismo sexual; instrumento psicométrico.

\begin{abstract}
This study aims at presenting a multi-factorial measurement of sexual liberalism/conservatism. New items were added to the Sexual Attitudes Questionnaire and two studies were developed. During the first study, the participants answered the Sexual Attitudes Questionnaire, divided in two sub-scales (Self and Other), and demographic questions. The results of the exploratory factor analysis showed a general factor of sexual liberalism/conservatism. In the second study, the participants answered the Sexual Liberalism/Conservatism Questionnaire (SLCQ), the Moral Conservatism Scale, the Moral Traditionalism Scale and demographic questions. By means of a confirmatory factorial analysis, the multi-factorial structure of the SLCQ was confirmed, revealing acceptable indexes of goodness-of-fit. The Cronbach's Alpha found to the second order factors were .88 (Self) and .90 (Other). All factors of liberalism correlated themselves with each other and with the conservatism and traditionalism scales, corroborating the convergent validity of the psychometric instrument, wich proved its adequacy for use in the Brazilian context.

Keywords: Sexual liberalism; sexual conservatism; psychometric instrument.
\end{abstract}

De acordo com Rohmann (2000), o liberalismo é uma doutrina política, social e econômica que, em sua concepção clássica, enfatiza a liberdade individual. Contrariamente, o conservadorismo enfatiza a tradição e é resistente a mudanças, especialmente as de natureza rápida e avassaladora, compreendendo o progresso como proveniente do saber plantado nas virtudes e nos valores do passado. Knight (1993) procura dar definições de liberalismo/conservadorismo de forma a clarificar a concepção destes construtos. Para esta autora, liberalismo é um conjunto de crenças políticas, econômicas, religiosas, educacionais e sociais que enfatizam a

\footnotetext{
* Endereço para correspondência: Valeschka M. Guerra/ Valdiney Veloso Gouveia, Centro de Ciências Humanas, Letras e Artes (CCHLA), Departamento de Psicologia, Campus Universitário, s/n, Universidade Federal da Paraíba, Castelo Branco, João Pessoa, PB, 58051-900.E-mail: vvgouveia@uol.com.br e valeschka@gmail.com.

Este artigo é parte da dissertação de Mestrado da primeira autora, sob orientação do segundo autor. Contou com bolsa de Demanda Social (CAPES) e Produtividade em Pesquisa, instituição a qual os autores agradecem. Desejam ainda expressar seus agradecimentos a dois revisores anônimos, cujas contribuições ajudaram a melhor uma versão prévia deste artigo.
}

liberdade do indivíduo, a discussão e tolerância de diferentes visões, a mudança social, o igualitarismo e os direitos das minorias. Por outro lado, o conservadorismo é entendido como um conjunto de crenças políticas, econômicas, religiosas, educacionais e sociais, caracterizado pela ênfase no status quo e na estabilidade social, na religião, na tradição e na moralidade.

De acordo com Ten (1999), as circunstâncias sociais que fazem surgir o liberalismo derivam do conflito e da diversidade. Neste conjunto de crenças, a virtude central é a tolerância às diferenças. Para os liberais, a neutralidade da lei deve ser mantida de forma a respeitar as pessoas como seres independentes e livres, capazes de decidirem por si mesmas. Assim, indivíduos considerados "desviantes" da norma não devem ser punidos, pois seus atos não são considerados prejudiciais aos direitos de outros indivíduos, nem à segurança social. Desta forma, o argumento liberal não permite tentativas legais de penalização da diferença. Os liberais podem até compartilhar os julgamentos negativos de conservadores sobre modos particulares de conduta, sem 
que esses julgamentos, no entanto, sirvam de base para uma intervenção legal e social. Assim, os argumentos liberais protegem as práticas homossexuais, por exemplo, porque estes relacionamentos indicam escolhas de seres individuais.

Robinson (1993) mostra que as maiores divergências entre liberais e conservadores são em tópicos relacionados à moralidade e ao estilo de vida, tais como a legalização da maconha. Contudo, o tema que mais separa os liberais dos conservadores é o ato sexual, especialmente no que diz respeito às relações extraconjugais; tal separação diminui no que diz respeito à economia e ao controle de armas, por exemplo. No General Social Survey (GSS) são questões acerca do estilo de vida que mais distinguem os auto-identificados como liberais dos conservadores. Foram estimadas diferenças de 20 a $25 \%$ entre liberais e conservadores em apoio a tópicos como a descriminalização da maconha e os atos sexuais homossexuais e pré-maritais (Robinson, 1993). Deste modo, é mais em assuntos morais do que políticos que as opiniões se colocam em extremos ideológicos.

Em geral, os termos liberal e conservador são percebidos como compondo uma única dimensão - quanto mais liberais os indivíduos são, menos conservadores serão considerados. Portanto, indivíduos que pontuam baixo nas escalas identificadas como medidas de conservadorismo são freqüentemente chamados de liberais, e vice-versa. Knight (1993) afirma que, no entanto, as dimensões econômicas e sociais existem separadamente. Isso permite que algumas pessoas, que se definem como liberais no que diz respeito à dimensão social, sejam economicamente conservadoras, não sentindo desconforto por possuírem atitudes dissonantes.

Wilson (1973, citado por Heaven \& Oxman, 1999) percebe o conservadorismo como um fator geral subjacente ao campo das atitudes sociais, e enfatiza a existência de uma correlação positiva do conservadorismo com o preconceito e as atitudes negativas frente a exogrupos. Assim, as situações cotidianas que envolvem a moralidade são as que realmente dividem as atitudes de grupos liberais e conservadores. Por esta razão, considerações morais e religiosas têm sido comumente incluídas nas medidas de conservadorismo. Portanto, ao se discutirem tópicos relacionados com o comportamento sexual e/ou certos tipos de condutas sociais, como fumar maconha, estar-se-iam discutindo, na verdade, tendências ideológicas liberais ou conservadoras acerca daquilo que é considerado moralmente correto. O presente artigo se centra no liberalismo / conservadorismo sexual, o que demanda maior atenção.

\section{Liberalismo / Conservadorismo Sexual}

Segundo Giddens (1993), o sexo na sociedade contemporânea não é conduzido às escondidas, mas permanece sendo continuamente alvo de discussões e pesquisas. Todas as mudanças culturais, decorrentes da Revolução Sexual da década de 1960 com o lançamento da pílula anticoncepcional, e os diversos estudos realizados tiveram grande impacto sobre as concepções difundidas na sociedade ocidental e no pensamento científico mundial acerca do sexo, da sexualidade e do gênero.
De acordo com Strey (1999), o termo sexo teve seu significado alterado e diz respeito, hoje, exclusivamente aos caracteres biológicos que permitem a reprodução humana e definem as características anatômicas e fisiológicas específicas. Quando este conceito passa a incluir as características psicológicas típicas de cada sujeito, seus comportamentos, interesses, estilos de vida, papéis sociais definidos e a consciência de si, é considerado gênero (D’Amorim, 1993). Para Strey (1999) o vocábulo gênero permite pensar e discutir a respeito do sexo em termos históricos e sócioculturais, sendo considerado um elemento fundamental na estruturação das relações sociais (Kahhale, 2001).

Pasquali, Souza e Tanizaki (1985) afirmam que a sexualidade pode ser melhor definida como um conjunto de fenômenos biológicos e psicológicos, que são influenciados pelo ambiente e se ligam às funções erótica e reprodutora, manifestando-se no ser humano em resposta a estímulos, os quais permitem que o indivíduo desfrute de prazer físico e/ou emocional, que pode ser direcionado para si mesmo ou para um objeto externo. De forma complementar, a sexualidade é entendida como algo inerente, que se manifesta, desde o momento do nascimento até a morte, de formas diferentes segundo cada etapa do desenvolvimento. Enquanto processo, é marcada pela história, cultura e afetividade, sendo expressa de forma singular em cada pessoa. "A sexualidade é, de forma bem mais ampla, expressão cultural" (Ministério da Educação e Cultura, 1996, p. 81).

Para Kahhale (2001) a sexualidade é um processo simbólico que constitui e expressa a identidade do sujeito, a forma como este vivencia sua intimidade, tanto na dimensão pública como particular, e a forma que ele dá às normas e à ética do grupo em que está inserido. Sendo assim, é "algo que é vivido no âmbito individual, mas cuja constituição nos sujeitos é possibilitada e caracterizada pelas normas e valores sociais" (p. 184).

Considerando as concepções apresentadas acerca da sexualidade, assim como a definição de Knight (1993) sobre o liberalismo / conservadorismo, sugere-se que o Liberalismo Sexualé um posicionamento social de aceitação e/ou afirmação da liberdade individual na área da sexualidade, em nome da autonomia pessoal. O Conservadorismo Sexual, por sua vez, é concebido como um posicionamento social de aceitação e/ou afirmação das normas e convenções sociais a respeito da sexualidade, em nome da tradição e da manutenção da sociedade.

Com o propósito de minorar uma lacuna existente nos estudos sobre as atitudes frente à sexualidade, este artigo teve como objetivo principal apresentar uma medida brasileira acerca do liberalismo / conservadorismo sexual. Para tanto, partiu-se do Questionário de Atitudes Sexuais (QAS), o que motiva sua descrição.

\section{Questionário de Atitudes Sexuais (QAS)}

Para medir atitudes liberais / conservadoras frente à sexualidade, Hannon, Hall, Gonzalez e Cacciapaglia (1999) desenvolveram a Sexual Attitudes Scale $(S A S)$, que foi administrada a estudantes universitários estadunidenses. Os itens originais foram desenvolvidos com base nos tópicos mais 
comumente discutidos em cursos de sexualidade humana realizados em universidades dos Estados Unidos. Para tanto, efetuou-se uma análise de conteúdo dos livros-texto utilizados nestes cursos, com uma amostra inicial de 90 itens. No entanto, como o objetivo da construção do instrumento original era verificar as atitudes frente a comportamentos sexuais específicos, foram retirados itens relativos ao aborto, métodos contraceptivos e relações maritais, considerados apenas indiretamente relacionados ao comportamento sexual em si, reduzindo a medida a 66 itens.

Estes se dividem em duas sub-escalas, referentes à própria sexualidade (Self Scale; $S S$ ) e à sexualidade do outro (Other Scale; OS). A primeira procura medir atitudes liberais / conservadoras frente à própria sexualidade, sendo subdividida em cinco fatores: auto-erotismo (por exemplo, Masturbação é uma boa saída quando estou solteiro/a), heterossexualidade (por exemplo, Faria sexo no primeiro encontro), homossexualidade (por exemplo, Aceito estar atraído/a por pessoas do mesmo sexo), variação sexual (por exemplo, Faria sexo grupal) e comercialização do sexo (por exemplo, Prestaria favores sexuais por dinheiro). A other scale é composta por itens que procuram medir atitudes liberais / conservadoras frente à sexualidade de outra pessoa, sendo esta do sexo oposto ao do respondente. Esta sub-escala também apresenta-se dividida nos mesmos cinco fatores: auto-erotismo (por exemplo, É aceitável que pessoas do sexo oposto utilizem a masturbação quando solteiras), heterossexualidade (por exemplo, É aceitável que pessoas do sexo oposto façam sexo no primeiro encontro), homossexualidade (por exemplo, É aceitável que pessoas do sexo oposto sintam-se atraídas por pessoas do mesmo sexo), variação sexual (por exemplo, É aceitável que pessoas do sexo oposto façam sexo grupal) e comercialização do sexo (por exemplo, É aceitável que pessoas do sexo oposto prestem favores sexuais por dinheiro). Os itens, construídos geralmente como assertivas, exprimem atitudes de aceitação e tolerância frente a determinados atos sexuais. As pessoas respondem em escala de cinco pontos, variando de $\mathbf{1}=$ Discor do totalmente a $\mathbf{5}=$ Concordo totalmente. Quanto maior a pontuação, maior seu liberalismo sexual.

O estudo de validação do instrumento original foi realizado com estudantes universitários do Norte da Califórnia, com idades variando de 17 a 55 anos $(M=23)$. A análise fatorial demonstrou a existência dos cinco fatores propostos para cada uma das sub-escalas, apresentando geralmente índices de consistência interna aceitáveis: Auto-erotismo (Self: $\alpha=0,88 ;$ Other: $\alpha=0,91$ ), Heterossexualidade (Self: $\alpha=0,67 ;$ Other: $\alpha=0,55)$, Homossexualidade (Self: $\alpha$ $=0,91$; Other: $\alpha=0,98)$, Variações sexuais (Self: $\alpha=0,77$; Other: $\alpha=0,87$ ) e Comercialização do sexo (Self: $\alpha=0,76$; Other: $\alpha=0,81$ ). Os resultados indicaram que os fatores se correlacionaram diretamente entre si. Os índices de consistência interna das sub-escalas foram satisfatórios ( Self: a = 0,93; Other: a = 0,96). Não foram encontradas diferenças de gênero nas pontuações médias dos participantes. No geral, estes apresentaram atitudes mais liberais acerca do comportamento do outro $(M=4,21 ; D P=1,92)$ do que da própria conduta $(M=2,47 ; D P=1,33), p<0,001$.
O presente estudo procurou inicialmente conhecer a estrutura fatorial do QAS. Portanto, apresenta-se a seguir o método utilizado para sua adaptação ao contex to brasileiro.

\section{Estudo 1 - Propriedades Psicométricas do QAS Método}

\section{Participantes}

Participaram 398 estudantes universitários de João Pessoa (205 mulheres; 193 homens), com idades entre 17 e 51 anos $(M=21,5 ; D P=4,76)$. A maioria indicou ser estudante de universidades particulares $(63,3 \%)$, solteira $(88,9 \%)$, de classe média $(66,4 \%)$ e católica $(73,1 \%)$. Estes se descrevem com um nível de religiosidade $(M=2,7 ; D P$ $=1,1)$ acima da mediana teórica da escala de resposta $(2$; amplitude de $\mathbf{0}=$ Nada religioso a $\mathbf{4}=$ Muito religioso). Quanto à sexualidade, $96 \%$ afirmaram ser heterossexuais e $70 \%$ disseram já ter tido a primeira relação sexual, com idadena data da iniciação sexual - variando de 11 a 27 anos $(M=$ $16,2 ; D P=2,31)$. Neste caso, as mulheres relataram um início mais tardio $(M=17,6 ; D P=2,05)$ do que os homens $(M=15,5 ; D P=2,10), t(262)=7,82 ; p<0,001$.

\section{Instrumento}

Questionário de Atitudes Sexuais. Compõe-se de cinco fatores: auto-erotismo, heterossexualidade, homossexualidade, variação sexual e comercialização do sexo (Hannon et al., 1999). Como os participantes do estudo eram primordialmente adolescentes e jovens adultos, os itens da escala original relativos ao fator variação sexual foram retirados devido ao tipo de atos sexuais que expressavam (sexo anal, sexo grupal, etc.). Esta decisão foi tomada na tentativa de evitar o presumível aumento de respostas em branco, a recusa de participantes em responder ou dos responsáveis em autorizar sua aplicação. No lugar destes itens foram incluídos outros que faziam referência ao sexo pré-marital (por exemplo, Para mim, manter relações sexuais antes do casamento não é aceitável; Manter relações sexuais antes do casamento vai me proporcionar um maior conhecimento do meu corpo, para a Self Scale; e Para pessoas do sexo oposto, manter relações sexuais antes do casamento não é aceitável; Manter relações sexuais antes do casamento vai proporcionar às pessoas do sexo oposto um maior conhecimento de seu corpo, para a Other Scale) e ao uso de camisinha (por exemplo, Só uso camisinha com meu/minha parceiro/a quando estou saindo com outras pessoas; Tenho vergonha de pedir para meu/minha parceiro/a usar camisinha, para a Self Scale; e Pessoas do sexo oposto só usam camisinha quando estão saindo com outras pessoas; Pessoas do sexo oposto têm vergonha de pedir para seus/suas parceiros/a usarem camisinha, para a Other Scale).

Um estudo piloto foi realizado para verificar a compreensão dos itens, traduzidos do original em inglês por um psicólogo bilíngüe e revisado por outro. Este foi realizado com 28 estudantes do ensino médio de uma escola pública de João Pessoa. Os participantes apresentaram idades variando de 14 a 20 anos $(M=15,5 ; D P=1,32)$, sendo $53 \%$ do sexo feminino. Sugeriu-se aos par ticipantes que indicassem os itens de difícil compreensão, opinando acerca de sua 
melhor redação. Este estudo resultou na retirada do item 24 da SS (Para mim, é aceitável manter relações homossexuais) e 19 da $O S$ (É aceitável que pessoas do sexo oposto mantenham relações homossexuais), devido à dificuldade apresentada pelos participantes de compreender seu conteúdo. Como os itens 20 (Teria relações sexuais com um parceiro do mesmo sexo) da $S S$ e 18 (É aceitável que a mulher mantenha relações sexuais com uma parceira do mesmo sexo) da $O S$ apresentavam o mesmo conteúdo semântico, decidiu-se eliminá-los, fazendo com que 32 passassem ao instrumento final.

Os participantes foram solicitados ainda a indicar sexo, idade, estado civil, religião, nível de religiosidade e classe social, além de responderem perguntas acerca de sua sexualidade: a orientação sexual, a vivência de intercurso sexual prévio e, em caso de resposta positiva, que idade tinha na época da primeira relação.

\section{Procedimento}

Os participantes responderam os questionários individualmente, porém em ambiente coletivo de sala de aula. Uma vez obtida a autorização do professor da disciplina, os aplicadores se apresentavam solicitando a colaboração voluntária dos estudantes. Foi-lhes informado que se tratava de uma pesquisa sobre condutas e atitudes sociais, não havendo respostas certas ou erradas. Uma vez tendo concordado em participar, estes preencheram um termo de livre consentimento. A todos foi assegurado que suas respostas seriam confidenciais. Em média, 20 minutos foram suficientes para concluir sua participação.

\section{Resultados}

Previamente, realizou-se uma análise do poder discriminativo dos itens deste questionário. Esta considerou grupos-critério internos, com os 50\% dos participantes com pontuações totais abaixo (grupo inferior) e acima (grupo superior) da mediana. Através do teste $t$, compararam-se as médias para cada item. Os resultados desta análise sugeriram retirar os itens 03, 06, 10, 22, 27 e 30 da $S S$ (Self Scale) e 04, 05, 11, 25, 26 e 31 da $O S$ (Other Scale), pois não diferenciaram estatisticamente os grupos comparados $(p>0,05)$. O leitor interessado poderá solicitar dos autores as tabelas correspondentes a estas análises. Desta forma, as escalas passaram à análise fatorial com 26 itens cada. A tabela correspondente poderá ser solicitada.

Nas análises fatoriais realizadas, inicialmente, foram verificados o Kayser-Meyer-Olkin (KMO) e Teste de Esfericidade de Bartlett, para comprovar a adequabilidade dos dados à realização da análise fatorial. Para a $S S$, o KMO encontrado foi de 0,88, e o Teste de Esfericidade de Bartlett, $?^{2}=$ $5709,35, p<0,001$. Para a $O S$, o KMO foi 0,90 e o Teste de Esfericidade de Bartlett, $?^{2}=7104,90, p<0,001$, considerados satisfatórios.

A análise PC (Principal Components) permitiu identificar, para ambas as escalas, a existência de seis componentes com valores próprios (eigenvalues) superiores a 1. Com relação à $S S$, o primeiro componente geral apresentou um valor próprio de 7,8, explicando $29 \%$ da variância total, enquanto o segundo componente apresentou um valor de 3,6 , explicando menos da metade desta variância (13\%). Do terceiro ao sexto componente, estes contribuíam para a explicação de menos de $10 \%$ da variância. Além disso, o primeiro componente integrou 25 dos 26 itens da medida, enquanto que todos os outros componentes abarcaram menos de dez itens. O mesmo padrão foi encontrado na $O S$, que apresentou seis componentes, dos quais o primeiro explicou cerca de $36 \%$ da variância, com valor próprio de 9,6 e integrando 25 itens. Do segundo componente em diante, o número de itens caiu para três em cada fator e a porcentagem de variância explicada foi reduzida para menos de $10 \%$. Portanto, decidiu-se por uma solução unifatorial, tanto para a $S S$ como a $O S$.

Para as duas escalas, adotou-se o critério de carga fatorial igual ou superior a $|0,30|$ para que o item fizesse parte do fator. A inclusão das sub-escalas $(S S$ e $O S$ ) tem o objetivo de comparar as pontuações dos participantes no mesmo fator em ambas medidas. Neste sentido, intuitivamente por questão de praticidade - optou-se por excluir de uma escala os itens retirados nas análises individuais da outra escala, tornando-as eqüitativas quanto ao número de itens. Portanto, no total foram excluídos da $S S$ os itens 05 e 12 , e na $O S$, os itens 01 e 28. Desta forma, ao fim desta análise cada uma das escalas apresentava 24 itens.

Por meio da Análise Fatorial dos Eixos Principais $(P A F)$, solicitando-se um único fator, a $S S$ apresentou valor próprio de 6,67 , explicando $27,8 \%$ da variância total, como descrito na Tabela 1 (próxima página).

De acordo com esta tabela, a medida apresenta uma estrutura unifatorial, com os 24 itens atendendo ao critério previamente estabelecido do valor mínimo das cargas fatoriais e apresentado um Alfa de Cronbach de 0,90. Os resultados destas análises realizadas com a $O S$ podem ser observados na Tabela 2 (página 51 ).

No caso da $O S$, seu fator único apresentou valor próprio de 8,38 , explicando $34,9 \%$ da variância total. Além disso, esta apresentou consistência interna (Alfa de Cronbach) de 0,92 .

\section{Discussão Parcial}

Depois da análise do poder discriminativo dos itens, da análise fatorial exploratória e do cálculo do Alfa de Cronbach, comprovou-se que, dos 33 itens que inicialmente compunham esta medida, 24 podem ser adequadamente empregados para avaliar um fator geral de atitudes frente à sexualidade. Uma análise do conteúdo dos itens revela que este fator geral pode ser interpretado como uma dimensão de liberalismo / conservadorismo sexual. Portanto, aparentemente, não se confirma a estrutura fatorial que previa a existência dos quatro fatores propostos pelos autores da escala original. Resta, porém, ponderar a natureza da análise fatorial empregada, cujo propósito é reunir o maior número de itens em fatores principais. Não pretende, pois, testar modelos teóricos.

A despeito do que antes se comentou, com o fim de efetuar uma análise fatorial confirmatória para comprovar a estrutura teoricamente multidimensional da medida em questão, 
Tabela 1

Análise Fatorial dos Eixos Principais da Self Scale (SS)

\begin{tabular}{|c|c|}
\hline Itens resumidos* & Cargas Fatoriais \\
\hline 16 casado(a), praticaria a masturbação como expressão sexual & 0,70 \\
\hline 26 solteiro(a), praticaria a masturbação como expressão sexual & 0,68 \\
\hline 21 usaria pornografia para me estimular sexualmente & 0,66 \\
\hline 18 usaria filmes eróticos para melhorar meu relacionamento & 0,64 \\
\hline o2 praticaria sexo com meu(minha) noivo(a) antes de casar & 0,64 \\
\hline O1 masturbação é uma boa saída quando estou solteiro(a) & 0,59 \\
\hline 32 faria sexo antes do casamento pra conhecer meu corpo & 0,57 \\
\hline O4 usaria pornografia para aprender técnicas sexuais & 0,57 \\
\hline 15 faria sexo só pelo meu prazer pessoal & 0,55 \\
\hline O7 sexo pré-marital me permite conhecer meu(minha) parceiro(a) & 0,55 \\
\hline 25 faria sexo no primeiro encontro & 0,53 \\
\hline 13 aceito, durante o sexo, pensar em outra pessoa & 0,53 \\
\hline 29 aceito estar atraída por pessoas do mesmo sexo & 0,49 \\
\hline O8 sexo pré-marital não é aceitável & 0,48 \\
\hline 33 mesmo envolvido(a) com alguém, aceito pensar em outra pessoa & 0,48 \\
\hline 14 prestaria favores sexuais por dinheiro & 0,46 \\
\hline 23 trocaria carícias com uma pessoa do mesmo sexo & 0,46 \\
\hline 20 teria relações com parceiro(a) do mesmo sexo & 0,45 \\
\hline 28 faria sexo por dinheiro & 0,44 \\
\hline 17 aceito que uma pessoa do meu sexo se insinue pra mim & 0,40 \\
\hline 11 faria mais sexo se usasse pornografia & 0,39 \\
\hline 31 pornografia é prejudicial & 0,39 \\
\hline o9 aceito estar atraído por pessoas de ambos os sexos & 0,37 \\
\hline 19 apareceria em materiais explícitos por dinheiro & 0,36 \\
\hline Número de itens & 24 \\
\hline Eigenvalue & 6,67 \\
\hline \% de variância explicada & 27,8 \\
\hline Alfa de Cronbach & 0,90 \\
\hline
\end{tabular}

Notas. ${ }^{*}$ Itens ordenados de acordo com a magnitude de suas cargas fatoriais. A versão ampliada dos itens deste questionário está disponível se solicitada aos autores.

consideraram-se os resultados obtidos da sua elaboração e realizou-se uma análise qualitativa dos 24 itens restantes, procurando agrupá-los em categorias e/ou fatores semanticamente consistentes. Esta decisão permitiu constituir os seguintes blocos de itens, com sua respectiva identificação:

1. Auto-erotismo. Concepção da masturbação como expressão alternativa da sexualidade (Por exemplo, $A$ masturbação é uma boa saída quando não estou envolvido/a com um/a parceiro/a, na $S S$; e É aceitável que as pessoas do sexo oposto utilizem a masturbação como uma expressão sexual quando não estão envolvidas com um/a parceiro/a, na $O S)$.

2. Sexo pré-marital. Concepção do sexo antes do casamento como uma forma de conhecer o próprio corpo e o/a companheiro/a (Por exemplo, Praticaria sexo com meu/minha noivo/a antes do casamento, na SS; e É aceitável que uma pessoa do sexo oposto mantenha relações sexuais com seu/sua noivo/a antes do casamento, na $O S$ ).

3. Pornografia. Visão do uso da pornografia com fins de aprimorar o relacionamento sexual (Por exemplo, Eu não utilizaria pornografia porque é prejudicial, na $S S$; e
Pessoas do sexo oposto não deveriam utilizar materiais pornográficos porque é prejudicial, na $O S$ ).

4. Homossexualidade. Aceitação de atos homossexuais (Por exemplo, Trocaria carícias com uma pessoa do mesmo sexo, na $S S$; e É aceitável que pessoas do sexo oposto troquem carícias com pessoas do mesmo sexo, na $O S$ ).

5. Comercialização do sexo. Relação dos atos sexuais com ganhos financeiros (Por exemplo, Prestaria favores sexuais por dinheiro, na $S S$; e Acho aceitável que pessoas do sexo oposto prestem favores sexuais por dinheiro, na $O S$ ).

6. Outros. Itens diversos (Por exemplo, Teria relações sexuais apenas buscando meu prazer pessoal, na $S S$; e $E^{\prime}$ aceitável que pessoas do sexo oposto tenham relações sexuais apenas buscando seu prazer pessoal, na $O S$ ).

Inicialmente, o grupo denominado Outros, por ser constituído por itens semanticamente diversos, torna-se, conseqüentemente, de difícil interpretação e rotulação sob uma categoria teoricamente consistente. Portanto, decidiu-se pela exclusão destes itens. Além disso, os itens 09 da $S S$ (Aceito estar atraído/a por pessoas de ambos os sexos) e 12 da $O S$ (É aceitável que pessoas do sexo oposto sintam-se atraídas por 
Tabela 2

Análise Fatorial dos Eixos Principais da Other Scale (OS)

\begin{tabular}{lc}
\hline Itens resumidos* & Cargas Fatoriais \\
\hline 21 atração por pessoas do mesmo sexo & 0,78 \\
18 manter relações com alguém do mesmo sexo & 0,76 \\
O9 usar pornografia para melhorar seu relacionamento sexual & 0,74 \\
29 troquem carícias com pessoas do mesmo sexo & 0,73 \\
12 estar atraído(a) por pessoas de ambos os sexos & 0,72 \\
O8 solteiros praticar a masturbação como forma de expressão & 0,70 \\
13 concordar que pessoas do mesmo sexo se insinuem & 0,70 \\
O3 usar pornografia para estimulação sexual & 0,70 \\
27 solteiros usariam masturbação como expressão sexual & 0,67 \\
20 casados, podem praticar a masturbação como expressão & 0,64 \\
15 usar pornografia para aprender novas técnicas & 0,62 \\
23 manter relações antes do casamento com o noivo & 0,58 \\
16 fazer sexo no primeiro encontro & 0,57 \\
22 fazendo sexo buscando seu prazer sexual & 0,53 \\
33 prestem favores sexuais por dinheiro & 0,52 \\
O7 aparecer em materiais explícitos por dinheiro & 0,51 \\
O6 fazer sexo por dinheiro & 0,51 \\
24 envolvidos em um relacionamento podem pensar em outros & 0,47 \\
30 sexo pré-marital proporciona conhecimento da relação & 0,46 \\
32 sexo pré-marital proporciona conhecimento do corpo & 0,44 \\
O2 durante o ato, é aceitável pensar em outra pessoa & 0,41 \\
17 pornografia é prejudicial & 0,39 \\
14 sexo pré-marital não é aceitável & 0,34 \\
Eigenvalue & 0,30 \\
Alfa de Cronbach & 0,92 \\
\hline
\end{tabular}

Notas. *Itens ordenados de acordo com a magnitude de suas cargas fatoriais. A versão ampliada dos itens deste questionário está disponível se solicitada aos autores.

pessoas de ambos os sexos), do fator teórico Homossexualidade, foram excluídos por representarem a bissexualidade e não a homossexualidade propriamente, como ocorre com os outros itens deste fator.

O fator Comercialização do sexo, embora possa ser relevante para integrar um fator geral de liberalismo conservadorismo sexual, diverge do propósito dos demais fatores, que têm enfatizado o sexo como um aspecto positivo, seja para a obtenção direta do prazer, o interrelacionamento entre pessoas ou a aprendizagem / estimulação da prática sexual. Além disso, este fator reuniu o menor número de itens, o que implica menor variabilidade de resposta dos participantes e dificulta avaliar em que medida poderia estar relacionado com as demais variáveis pesquisadas. Este conjunto de argumentos foi levado em conta para não incluir a Comercialização do sexo no modelo a ser testado sobre as atitudes sexuais.

Portanto, ao cabo chegou-se a um instrumento estruturalmente diferente daquele apresentado originalmente. Com os quatro fatores restantes (auto-erotismo, sexo pré-marital, pornografia e homossexualidade), constituídos por 16 itens de cada escala ( $S S$ e $O S)$, compôs-se o Questionário de
Liberalismo / Conservadorismo Sexual(QLCS), a ser testado mediante o uso de uma análise fatorial confirmatória, procurando comprovar a existência destes quatro fatores de primeira ordem e de um fator de segunda ordem, denominado como Liberalismo / Conservadorismo Sexual, objetivo do segundo estudo.

\section{Estudo 2 - Análise Fatorial Confirmatória do QLCS Método}

\section{Participantes}

Participaram desta pesquisa 313 estudantes de uma universidade pública de João Pessoa, sendo 159 mulheres e 154 homens, com idades entre 17 e 56 anos $(M=21,8$; $D P=4,88)$. A maioria indicou ser solteira $(87,5 \%)$ e de classe sócio-econômica média (64,9\%). Quanto à religião, a maioria disse ser católica (52,3\%) e se considerar com um nível de religiosidade $(M=2,1 D P=1,2)$ por volta da pontuação mediana teórica (2; amplitude de $\mathbf{0}=$ Nada religioso a $\mathbf{4}=$ Muito religioso). Além das perguntas demográficas, foram inseridas questões relativas à sexualidade: $93 \%$ disseram ser heterossexuais; $70 \%$ afirmaram ter tido a primeira 
relação sexual, com idade - na data da iniciação sexual - variando de 9 a 28 anos $(M=16,7 ; D P=2,65)$. As mulheres tiveram seu primeiro intercurso sexual em idade mais tardia $(M=18,4 ; D P=2,62)$ do que os homens $(M=$ $15,7 ; D P=2,10), t(210)=8,12 ; p<0,001$.

\section{Instrumentos}

Para avaliar o liberalismo sexual dos participantes, foi utilizado o Questionário de Liberalismo / Conservadorismo Sexual (QLCS), desenvolvido a partir do instrumento de Hannon et al. (1999), já descrito anteriormente.

Escala de Conservadorismo Moral. Elaborada por Wald, Owen e Hill (1988, citados por Knight, 1993), apresenta dez itens relativos aos aspectos morais do liberalismo e conservadorismo, principalmente no que diz respeito aos papéis sexuais tradicionais e a condutas sociais específicas (por exemplo, Homens e mulheres deveriam ter os mesmos direitos legais; $O$ governo deveria proibir o uso particular de maconha), respondidos em escala de cinco pontos, variando de $\mathbf{1}=$ Concordo totalmente $\mathbf{5}=$ Discordo totalmente. Esta escala foi validada em amostras de congregações religiosas na região Sul dos Estados Unidos, tendo reportado consistência interna (Alfa de Cronbach, $\alpha$ ) de 0,80. No contex to brasileiro os resultados foram mais moderados; o componente único (análise $P C$ ) apresentou valor próprio de 1,81, explicando $18 \%$ da variância total $(\alpha=0,47)$.

Escala de Tradicionalismo Moral. Desenvolvida por Conover e Feldman (1986, citados por Knight, 1993), mede o apoio a valores sociais e morais conservadores, sendo apresentada como teoricamente relacionada, mas distinta das medidas de fundamentalismo religioso e autoritarismo. É constituída por oito itens, formulados como sentenças abstratas que enfocam as avaliações de mudanças nos valores e nas práticas morais da sociedade (por exemplo, Há muita liberdade sexual hoje em dia; Novos estilos de vida estão contribuindo para a destruição de nossa sociedade), sendo respondidos em escala de cinco pontos, variando de $\mathbf{1}=$ Concordo totalmente a $\mathbf{5}=$ Discordo totalmente. Seu Alfa de Cronbach $(\alpha)$ quando da elaboração foi 0,74 . No presente estudo o componente único (análise $P C$ ) apresentou valor próprio de 3,12 , explicando $39 \%$ da variância total $(\alpha=0,77)$.

As escalas de conservadorismo e tradicionalismo moral tiveram alguns itens invertidos para que medissem na mesma direção, ou seja, quanto maior a pontuação, mais atitudes conservadoras. Esperava-se que estas se correlacionassem negativamente com as sub-escalas de liberalismo sexual. Os participantes foram solicitados ainda a responder, além de questões demográficas constantes no primeiro estudo, o nível sócio-econômico e o quanto se avaliam como liberais ou conservadoras no que diz respeito à sexualidade, devendo ser indicado em uma escala de cinco pontos $(\mathbf{0}=$ Muito conservador e $\mathbf{4}=$ Muito liberal $)$.

\section{Procedimento}

Os participantes foram solicitados a responder os questionários individualmente, em ambiente coletivo de sala de aula. Depois de obtida a autorização do professor da disciplina, os aplicadores solicitavam a colaboração voluntária dos estudantes. Foi-lhes informado que se tratava de uma pesquisa sobre condutas e atitudes sociais, não havendo respostas certas ou erradas. Estes preencheram um termo de livre consentimento. A todos foi enfatizado o caráter confidencial dos dados, assim como a natureza voluntária da participação. Em média, 30 minutos foram suficientes para concluir sua participação.

\section{Resultados}

\section{Análise Fatorial Confirmatória}

Considerando o objetivo principal da presente pesquisa, isto é, conhecer a validade de construto do Questionário de Liberalismo / Conservadorismo Sexual, foi elaborado um modelo acerca da sua estrutura fatorial. A análise fatorial confirmatória é adequada para a testagem da estrutura fatorial, pois permite: (a) a especificação de modelos teoricamente relevantes; (b) a identificação de fatores de primeira e segunda ordens; e (c) a comparação de modelos alternativos para determinar qual possui o melhor ajuste (BisquerraAlzina, 1989). O modelo final testado da $S S$ por meio do AMOS 4 pode ser observado na Figura 1.

Como é possível observar na Figura 1, a solução com os quatro fatores foi estabelecida para a $S S$. No geral, o modelo teórico se ajustou razoavelmente aos dados: a razão ?2/gl foi de 3,38, com GFI de 0,89, AGFI de 0,85 e $R M R S$ de 0,08. Além disso, a escala geral apresentou consistência interna (Alfa de Cronbach) de 0,88, sendo os índices específicos de cada fator também considerados satisfatórios: homossexualidade $(\alpha=0,90)$, sexo pré-marital $(\alpha=0,87)$, auto-erotismo $(\alpha=0,82)$ e pornografia $(\alpha=0,67)$. Com relação à $O S$, os resultados obtidos podem ser observados na Figura 2 (página 54).

Da mesma forma que na $S S$, a solução com quatro fatores específicos e um geral para a $O S$ também foi estabelecida, com um ajuste satisfatório do modelo aos dados. A razão ?2/gl foi igual a 1,87 , com $G F I=0,93$, $A G F I=0,91$ e $R M R S=0,06 . \mathrm{O}$ índice de consistência interna da escala geral foi de 0,90. Os Alfas dos fatores específicos também foram considerados aceitáveis: homossexualidade $(\alpha=0,93)$, auto-erotismo $(\alpha=0,87)$, sexo prémarital $(\alpha=0,81)$ e pornografia $(\alpha=0,70)$.

Em resumo, tanto para a $S S$ como para a $O S$ foi confirmada a existência de um fator de segunda ordem denominado Liberalismo / Conservadorismo Sexual e quatro de primeira ordem. O instrumento final é formado, assim, por 16 itens de cada escala. Posteriormente, procurou-se analisar a validade convergente desta medida.

\section{Validade Convergente}

Com o objetivo de testar a validade convergente do Questionário de Liberalismo / Conservadorismo Sexual (QLCS), procurou-se verificar a correlação entre as pontuações totais das suas sub-escalas com aquelas de conservadorismo e tradicionalismo moral. Foram calculadas ainda as correlações com o grau de religiosidade e o nível de conservadorismo auto-percebido dos participantes (Tabela 3). 


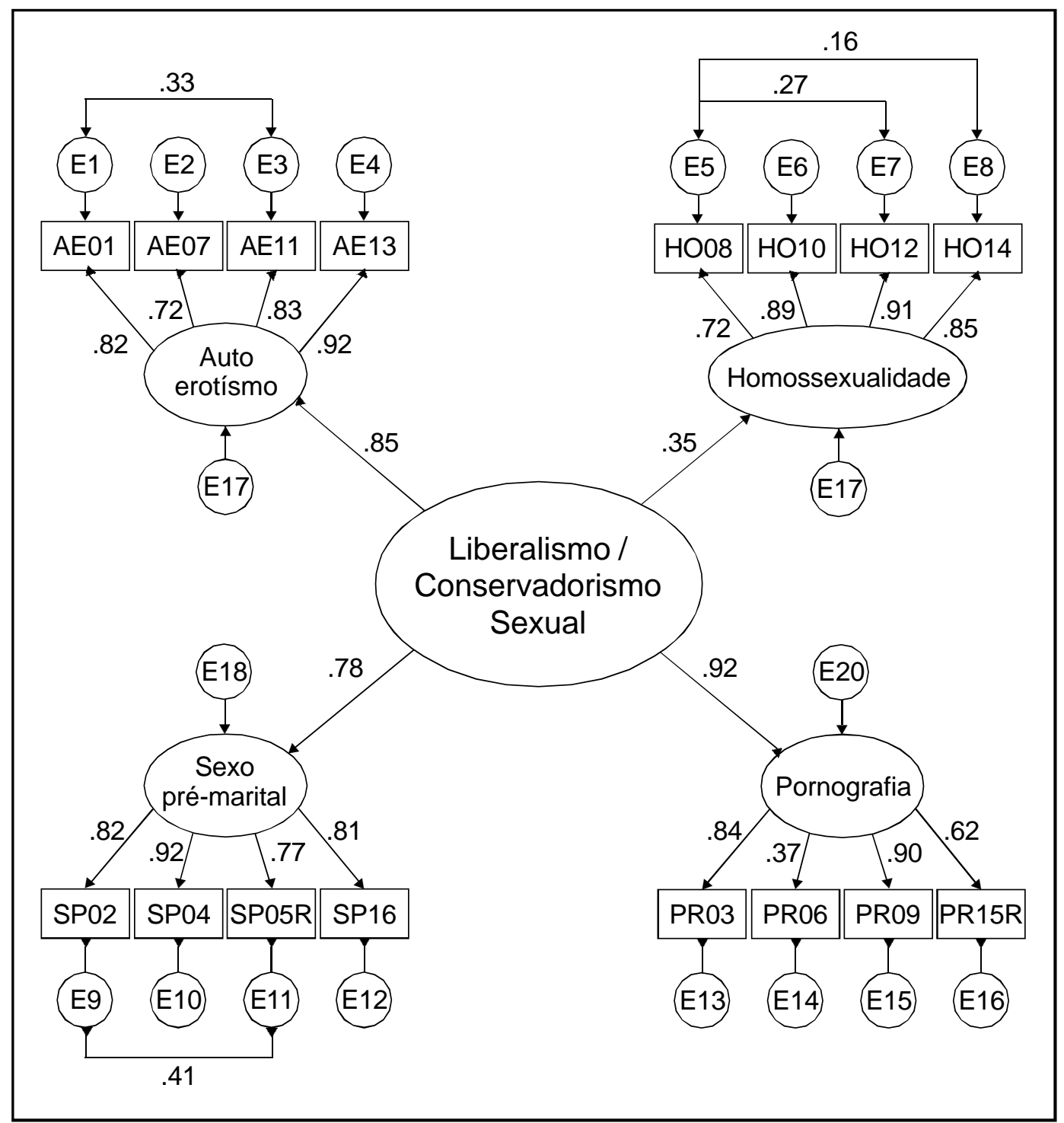

Figura 1. Comprovação da estrutura fatorial da medida referente à própria sexualidade $(S S)$.

Como pode ser observado nesta tabela, as pontuações totais do liberalismo sexual apresentaram correlações negativas com o conservadorismo moral ( $S S: r=-0,54, p<$ 0,001; OS: $r=-0,58, p<0,001)$ e tradicionalismo moral $(S S: r=-0,62, p<0,001 ; O S: r=-0,66, p<0,001)$, indican- do a convergência do conteúdo destas medidas. As pontuações totais de liberalismo sexual se correlacionaram negativamente com o grau de religiosidade (SS: $r=-0,43, p<$ 0,001; OS: $r=-0,44, p<0,001)$ e positivamente com o grau de conservadorismo / liberalismo auto-percebido ( $S S: r=0,61$,

Tabela 3

Correlatos do Liberalismo / Conservadorismo Sexual

\begin{tabular}{lccccccccc}
\hline Variáveis & $M$ & $D P$ & & & & & \\
\hline 1. Liberalismo geral (SS) & 3,0 & 0,80 & - & & & & \\
2. Liberalismo geral (OS) & 3,4 & 0,80 & $82^{*}$ & - & & & \\
3. Conservadorismo moral & 3,2 & 0,42 & $-54^{*}$ & $-58^{*}$ & - & & \\
4. Tradicionalismo moral & 2,6 & 0,73 & $-62^{*}$ & $-66^{*}$ & $57^{*}$ & - & \\
5. Grau de religiosidade & 2,1 & 1,21 & $-43^{*}$ & $-44^{*}$ & $31^{*}$ & $45^{*}$ & - \\
6. Grau de liberalismo & 2,5 & 0,94 & $61^{*}$ & $61^{*}$ & $-42^{*}$ & $-49^{*}$ & $-34^{*}$ \\
\hline
\end{tabular}

Notas: ${ }^{*} p<0,01$ (teste bi-lateral; eliminação pairwise de itens sem resposta). Omitiram-se os pontos decimais dos coeficientes de correlação. 


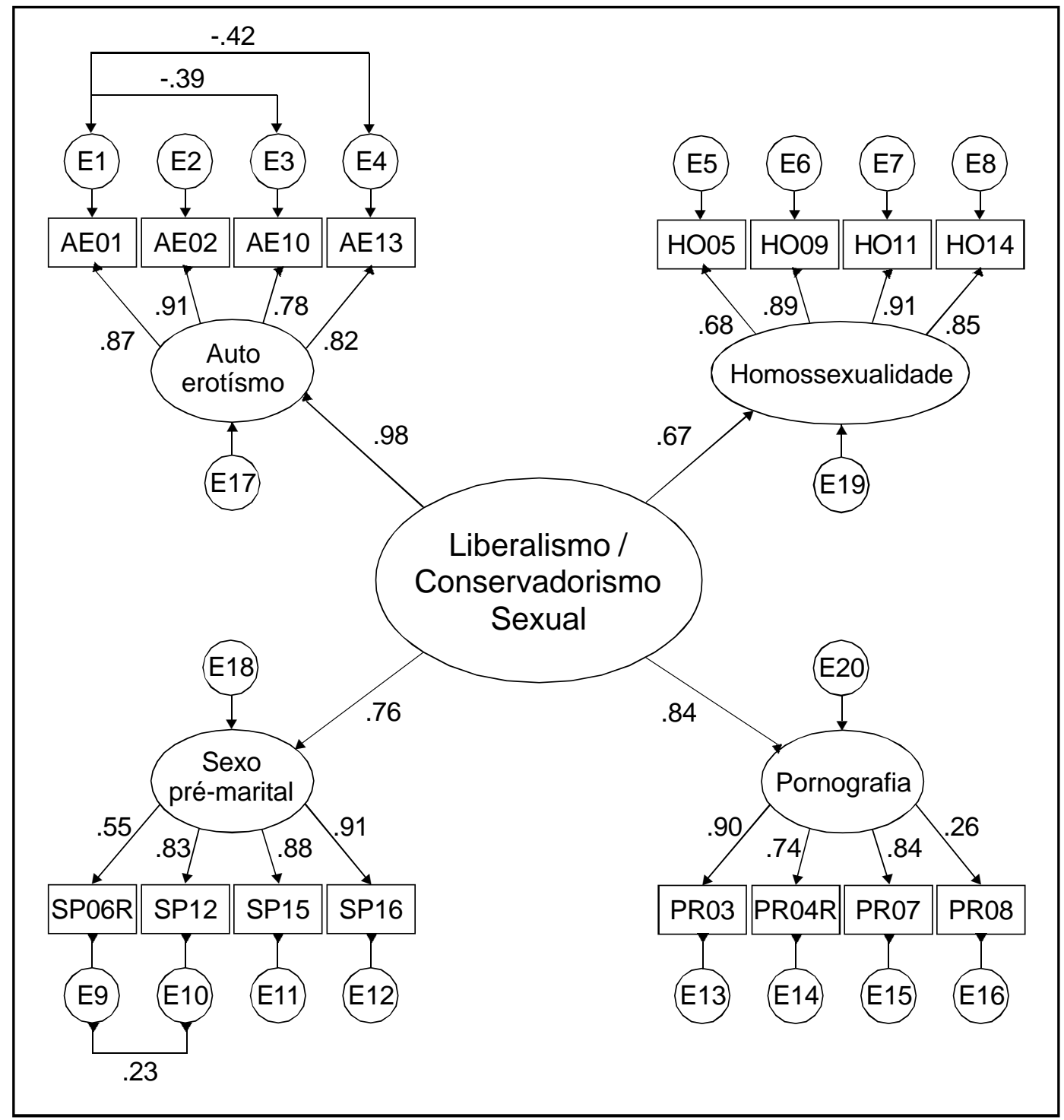

Figura 2. Comprovação da estrutura fatorial da medida referente à sexualidade do outro $(O S)$.

$p<0,001 ; O S: r=0,61, p<0,001)$. O conservadorismo e tradicionalismo moral se correlacionaram diretamente com o grau de religiosidade $(r=0,31$ e 0,45 , respectivamente; $p<0,001$ para ambos). Da mesma forma, o nível de liberalismo auto-percebido apresentou correlações inversas com o conservadorismo moral e tradicionalismo moral $(r=-0,42$ e $-0,49$, respectivamente; $p<0,001)$.

Finalmente, a média de liberalismo $(M=2,5 ; D P=0,93)$ auto-percebido dos participantes se situou acima do ponto mediano da escala de resposta (2; amplitude de $\mathbf{0}=$ Muito conservador a $\mathbf{4}=$ Muito liberal), $t(312)=46,97 ; p<0,001$, sugerindo que estes são mais liberais do que conservadores em temas de sexualidade.

\section{Discussão Geral}

O propósito principal deste estudo foi apresentar uma medida multi-fatorial do liberalismo / conservadorismo sexual, comprovando sua validade de construto e convergente. Espera-se que este tenha sido alcançado. Embora esta pesquisa ofereça contribuições para conhecer o liberalismo / conservadorismo sexual, não se descartam limitações. Particularmente, é necessário assinalar que as amostras não podem ser consideradas representativas da população paraibana, pois foi constituída exclusivamente por estudantes universitários. Não se conhece o padrão de resposta ao Questionário de Liberalismo / Conservadorismo Sexual na população geral. Neste sentido, espera-se que novos estudos possam ser realizados, com a aplicação deste instrumento em diferentes amostras, de forma a aprofundar o conhecimento acerca do liberalismo / conservadorismo sexual.

Além disso, a coleta de dados foi realizada com base em auto-relatos. Por conseguinte, os resultados apresentados são evidências acerca das atitudes e dos comportamentos sexuais reportados pelos participantes. Entretanto, não foi o propósito deste estudo efetuar generalizações. Pretendeu-se unicamente apresentar um instrumento acerca do construto liberalismo sexual que pudesse ser adequado para utilização em pesquisa no contex to brasileiro. Finalmente, 
cabe assinalar que a Escala de Conservadorismo Moral apresentou índice de consistência interna bem abaixo do que seria recomendado ( $\alpha=0,70$; Nunnally, 1991), o que demanda rever a pertinência de empregá-la em pesquisas futuras. Apesar desta limitação, sua correlação com o QLCS, indicação da validade convergente deste questionário, é consistente com a observada para a Escala de Tradicionalismo Moral. Feitos estes comentários, cabe considerar mais pormenorizadamente os resultados antes descritos.

\section{Estrutura Fatorial}

Inicialmente, exigiu-se conhecer os parâmetros psicométricos do Questionário de Atitudes Sexuais. Sua versão original possui 33 itens em cada sub-escala, num total de 66 itens, distribuídos entre os fatores Auto-erotismo, Heterossexualidade, Homossexualidade e Comercialização do sexo. Para a realização do presente estudo, os itens relativos a variações sexuais (sexo oral, anal etc.) foram substituídos por itens acerca de sexo pré-marital e o uso de camisinha. As análises estatísticas efetuadas no instrumento proposto (QLCS) sugeriram que esta medida poderia ser perfeitamente reduzida a 16 itens em cada sub-escala (total de 32 itens), avaliando as dimensões Auto-erotismo, Sexo pré-marital, Pornografia e Homossexualidade, com índices de consistência interna satisfatórios em ambas as sub-escalas (Self: $\alpha=0,88$; Other: $\alpha=0,90)$. Portanto, oferece-se aqui uma nova estrutura do liberalismo sexual, que poderá ser útil em estudos futuros, apresentando-se de modo mais parcimonioso.

\section{Validade Convergente}

Quanto à validade convergente do presente instrumento, as escalas de conservadorismo e tradicionalismo moral foram incluídas na pesquisa com o objetivo de verificar sua correlação com as sub-escalas propostas de liberalismo sexual. Neste sentido, as medidas de conservadorismo e tradicionalismo moral apresentaram correlações negativas com ambas as sub-escalas do liberalismo sexual, o que pode indicar uma convergência do conteúdo destas pontuações. Correlações positivas com o grau de religiosidade do participante também foram encontradas, tanto para o conservadorismo como o tradicionalismo moral, corroborando achados prévios acerca da relação entre o conservadorismo e a religiosidade (Joe, Jones \& Miller, 1981). Além disso, foi solicitado aos participantes que respondessem o quanto se consideravam conservadores / liberais com relação à sexualidade. Estas pontuações se correlacionaram positivamente com o liberalismo sexual dos participantes, tanto na sub-escala Selfcomo na Other, e negativamente com o conservadorismo e tradicionalismo moral. Tais achados parecem comprovar a validade convergente deste instrumento.

\section{Atitudes Liberais / Conservadoras}

Além dos resultados referentes às correlações do liberalismo / conservadorismo sexual com o nível de religiosidade e de liberalismo auto-percebido dos participantes, é interessante observar a tendência liberal destes com relação aos temas abordados, principalmente no que diz respeito à sexualidade do outro, o que corrobora o estudo de
Hannon et al. (1999). A maior aceitação com relação ao outro é característico de um posicionamento ideológico liberal que, como afirmam Knight (1993) e Ten (1999), enfatiza a liberdade individual e, principalmente, a tolerância às diferenças. Tal posicionamento não é aceito pelos conservadores, que enfatizam um padrão social de comportamento que deve ser seguido e respeitado por todos (Knight, 1993), principalmente no que diz respeito à moralidade e ao estilo de vida (Robinson, 1993).

No entanto, esta tendência liberal pode ser atribuída a outros fatores. A maior liberalização do comportamento sexual dos jovens é amplamente divulgada na literatura (Caron \& Moskey, 2002; McCabe \& Cummins, 1998; Risman $\&$ Schwartz, 2002). Se considerado que a amostra é constituída, basicamente, por jovens (Média de idade $=21 ; D P=$ $4,88)$, é esperado que este padrão seja observado. Além disso, de acordo com Tamayo (1988, 1994), os universitários priorizam mais um padrão valorativo que enfatiza a tolerância e a abertura à mudança do que a população geral.

\section{Pesquisas Futuras}

Recomenda-se que outras variáveis sejam associadas ao liberalismo sexual, de forma a garantir um estudo mais minucioso do mesmo. A análise das características demográficas, como diferenças de gênero, idade e religião, que não foram levadas em consideração neste estudo, mereceriam maior atenção. Caberia, igualmente, sugerir o uso da Teoria da Ação Racional, amplamente utilizada em pesquisas acerca de comportamentos na área da saúde (Dias, 1995; Gonçalves \& Dias, 1999). De acordo com Ajzen (2001), o melhor preditor para o comportamento individual é a intenção comportamental, ou seja, as pessoas agem de acordo com suas intenções. Estas, por sua vez, são determinadas pelas atitudes frente ao comportamento em questão (âmbito pessoal) e pela norma subjetiva (âmbito social). Tal teoria pode ser de grande importância para o estudo da conduta sexual geral, mediante a construção de instrumentos que abarquem o tema e sirvam como base para a elaboração de modelos teóricos que expliquem este comportamento e que possam ser associados às atitudes liberais / conservadoras frente à sexualidade.

Outro ponto a ser levado em consideração é a relação entre o liberalismo sexual e o comportamento real dos participantes. Poderiam ser incluídas questões acerca do tipo de experiência sexual já vivenciada pelos respondentes no que diz respeito aos quatro fatores do liberalismo (auto-erotismo, sexo pré-marital, pornografia e homossexualidade), de forma a verificar em que medida sua pontuação nestes fatores estaria correlacionada com suas experiências respectivas.

Finalmente, ao compreender a sexualidade enquanto uma construção permanente, influenciada pelas relações interpessoais e pelo contex to social, o construto liberalismo / conservadorismo sexual pode estar relacionado a alguns construtos que parecem ser importantes para sua explicação. Ao conceber os valores humanos como representações cognitivas das necessidades, que ajudam a orientar o 
comportamento dos indivíduos, estes podem ser considerados importantes para a compreensão do liberalismo / conservadorismo sexual (Hardy \& Rafaelli 2003; Heaven \& Oxman, 1999; McCree, Wingood, DiClemente, Davies \& Harrington, 2003). Nesta direção, caberia igualmente conhecer a relação do liberalismo sexual com a desejabilidade social, definida como uma tendência inconsciente de criar uma impressão positiva de si mesmo, evitar críticas e receber a aprovação geral (Crowne \& Marlowe, 1960). Essa tendência pode ter influência sobre os construtos estudados e as respostas dadas aos instrumentos de medida, devido ao fato de que o objeto de estudo é de natureza privada e pode abranger comportamentos e sentimentos socialmente indesejáveis.

\section{Referências}

Ajzen, I. (2001). Nature and operation of attitudes. Annual Reviere of Psychology, 52, 27-58.

Bisquerra-Alzina, R. (1989). Introducción conceptual al análisis multivariable: Un enfoque informático con los paquetes SPSS-X, BMDP, LISREL y SPAD. Barcelona, España: PPU.

Caron, S., \& Moskey, E. (2002). Changes over time in teenage sexual relationships: Comparing the high school class of 1950 , 1975, and 2000. Adolescence, 37, 516-526.

Crowne, D., \& Marlowe, D. (1960). A new scale of social desirability independent of psychopathology. Journal of Consulting Psychology, 24, 349-354.

D’Amorim, M. A. (1993). Papel de gênero e atitudes acerca da sexualidade. Psicologia: Teoria e Pesquisa, 5, 71-83.

Dias, M. R. (1995). AIDS, comunicação persuasiva e prevenção: Uma aplicação da Teoria da Ação Racional. Tese de Doutorado nãopublicada, Universidade de Brasília, DF.

Giddens, A. (1993). A transformação da intimidade: Sexualidade, amor e erotismo nas sociedades modernas. São Paulo, SP: Editora da Universidade Estadual Paulista.

Gonçalves, S., \& Dias, M. (1999). A prática do auto-exame da mama em mulheres de baixa renda: Um estudo de crenças. Estudos de Psicologia, 4, 141-159.

Hannon, R., Hall, D., Gonzalez, V., \& Cacciapaglia, H. (1999, July 1). Revision and reliability of a measure of sexual attitudes. Electronic Journal of Human Sexuality, 2. Retirado em 02 ago. 2003, de http://www.ejhs.org/volume2/hannon/attitudes.htm

Hardy, S., \& Raffaelli, M. (2003). Adolescent religiosity and sexuality: An investigation of reciprocal influences. Journal of Adolescence, 26, 731-739.
Heaven, P., \& Oxman, L. (1999). Human values, conservatism and stereotypes of homosexuals. Personality and Individual Differences, 27, 109-118.

Joe, V., Jones, R., \& Miller, P. (1981). Value pattern of a conservative. Personality and Individual Differences, 2, 25-29.

Kahhale, E. M. (2001). Subsídios para reflexão sobre sexualidade na adolescência. In A. M. Bock, M. G. Gonçalves \& O. Furtado (Eds.), Psicologia sócio-histórica: Uma perspectiva crítica em psicologia (pp. 179-191). São Paulo, SP: Cortez.

Knight, K. (1993). Liberalism and conservatism. In J. Robinson, P. Shaver \& L. Wrightsman (Eds.), Measures of social psychological attitudes (pp. 59-158). San Diego, CA: Academic Press.

McCabe, M., \& Cummins, R. (1998). Sexuality and quality of life among young people. Adolescence, 33, 761-773.

McCree, D., Wingood, G., DiClemente, R., Davies, S., \& Harrington, K. (2003). Religiosity and risky sexual behavior in African-American adolescent females. Journal of Adolescent Health, 33, 2-8.

Ministério da Educação e Cultura. (1996). Parâmetros curriculares nacionais: Orientação sexual. Retirado em 10 jun. 1997, de http:/ /www.bibvirt.futuro.usp.br/textos/humanas/educacao/pcns/ fundamental/sexual.html

Nunnally, J. C. (1991). Teoría psicométrica. México: Trillas.

Pasquali, L., Souza, M., \& Tanizaki, T. (1985). Escala de atitude diante da sexualidade. Psicologia: Teoria e Pesquisa, 1, 175-194.

Risman, B., \& Schwartz, P. (2002). After the sexual revolution: Gender politics in teen dating. Contexts, 1, 16-27.

Robinson, J. P. (1993). Appendix: Ideological trends from General Social Survey items. In J. Robinson, P. Shaver \& L. Wrightsman (Eds.), Measures of social psychological attitudes (pp. 59-158). San Diego, CA: Academic Press.

Rohmann, C. (2000). O livro das idéias. São Paulo, SP: Campus.

Strey, M. (1999). Gênero. In M. G. Jacques (Ed.), Psicologia social contemporânea (pp. 181-198). Petrópolis, RJ: Vozes.

Tamayo, A. (1988). Influência do sexo e da idade sobre o sistema de valores. Arquivos Brasileiros de Psicologia, 38, 91-104.

Tamayo, A. (1994). Hierarquia de valores transculturais e brasileiros. Psicologia: Teoria e Pesquisa, 10, 269-285.

Ten, C. L. (1999). Liberal toleration. Social Research, 66, $1167-$ 1190 . 